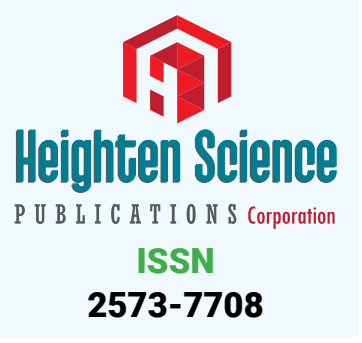

*Address for Correspondence: Mona Mlika, Department of Pathology, Abderrahman Mami Hospital, Tunisia, Tel: (00216) 985388 62; Fax: 0021671710780; Email: mlika.zorgati. mona@hotmail.com

Submitted: 13 December 2016

Approved: 18 January 2017

Published: 20 January 2017

Copyright: @ 2017 Mlika et al. This is an open access article distributed under the Creative Commons Attribution License, which permits unrestricted use, distribution, and reproduction in any medium, provided the original work is properly cited.

Keywords: Diagnosis; Pathology; Thymoma
Case Report

\section{Cystic Micronodular Thymoma. Report of a Case}

\author{
Mona Mlika*1,2, Adel Marghli ${ }^{3}$ and Faouzi Mezni ${ }^{1,2}$ \\ 'Department of Pathology, Abderrahman Mami Hospital, Université de Médecine, Tunis El \\ Manar, Tunisia \\ ${ }^{2}$ Research Unit: RU12/SP16 \\ ${ }^{3}$ Department of Thoracic Surgery, Abderrahman Mami Hospital, Tunisia
}

\section{ABSTRACT}

Micronodular thymoma is a rare subtype of thymoma with less than 20 cases published in the English literature. These tumours have been reported with thymoma or thymic cyst. The authors describe a new case of micronodular thymoma in a 68-year-old-patient which is well documented and particular by its cystic degeneration which hasn't been described yet. Micronodular thymoma is a rare variant of thymoma with a challenging diagnosis. Clinicians must be aware of this entity in order not to confuse it with a thymic cyst.

\section{INTRODUCTION}

Mediastinal tumours are represented in approximately $60 \%$ of the cases by thymomas. According to the 2015 WHO classification, the thymomas are classified according to 2 major characteristics. The first one is the shape of the epithelial cells. These cells may be atrophic (type A) or bio-active (type B). The second criteria is the amount of immature lymphocytes. According to these criteria, the type B thymoma is divided into B1, B2 and B3 thymoma depending on the atypical features and the amount of immature lymphocytes [1].

The clinical perspective of the classification 2015 World Health Organization Classification of Tumors of the Thymus has been strengthened by involving experts from radiology, thoracic surgery and oncology by incorporating state-of-the-art positron emission tomography/computed tomography images and by depicting prototypic cytological specimens. This makes the thymus section of the new WHO Classification of Tumours of the Lung, Pleura, Thymus and Heart a valuable tool for pathologists, cytologists, and clinicians alike [2,3].

\section{CLINICAL SUMMARY}

A 68-year-old patient without a particular past medical history presented chest pain, dyspnea and dysphagia lasting for 2 years. Physical exam was normal. Chest-xray showed a mediastinal enlargement. Chest-CT-scan revealed a partially cystic preaortic mass. A thymectomy was performed.

\section{PATHOLOGICAL FINDINGS}

Gross examination revealed a mass measuring $7 \mathrm{~cm}$, partially cystic and lobulated. Microscopic exam revealed an encapsulated tumor, largely cystic with many epithelial nodules focally confluent separated by a lymphoid stroma with some reactive follicles. 
Tumour cells were of spindle shape with an abundant cytoplasm and atypical nuclei. This tumour was encapsulated with a thick capsule (Figure 1a, b). Immunohistochemical study was performed and showed the positivity of the tumour cells with cytokeratin and the epithelial membrane antigen. The lymphocytes forming follicles expressed CD20 antigen (Figure 1c, d). The immature lymphocytes which were observed in the stroma expressed the Tdt (Figure 1e). The diagnosis of cystic miconodular thymoma with lymphoid stroma of stage I according to the Masaoka classification was retained.

\section{DISCUSSION}

The authors describe a rare observation about a cystic micronodular thymoma diagnosed on a surgical specimen. Micronodular thymoma is a rare subtype of thymoma according to the 2015 WHO classification. Since the first description in 1999 by Moran, less than 20 cases have been published in the literature [4]. These tumours present the diagnostic features of thymoma including lobulation and the co-existence of epithelial cells and immature lymphocytes. Microscopically, micronodular thymoma is characterized by multiple, discrete or focally confluent epithelial nodules separated by an abundant lymphocytic stroma that may contain follicles with prominent germinal centres surrounded by mantle and enlarged marginal zones. There is a variable number

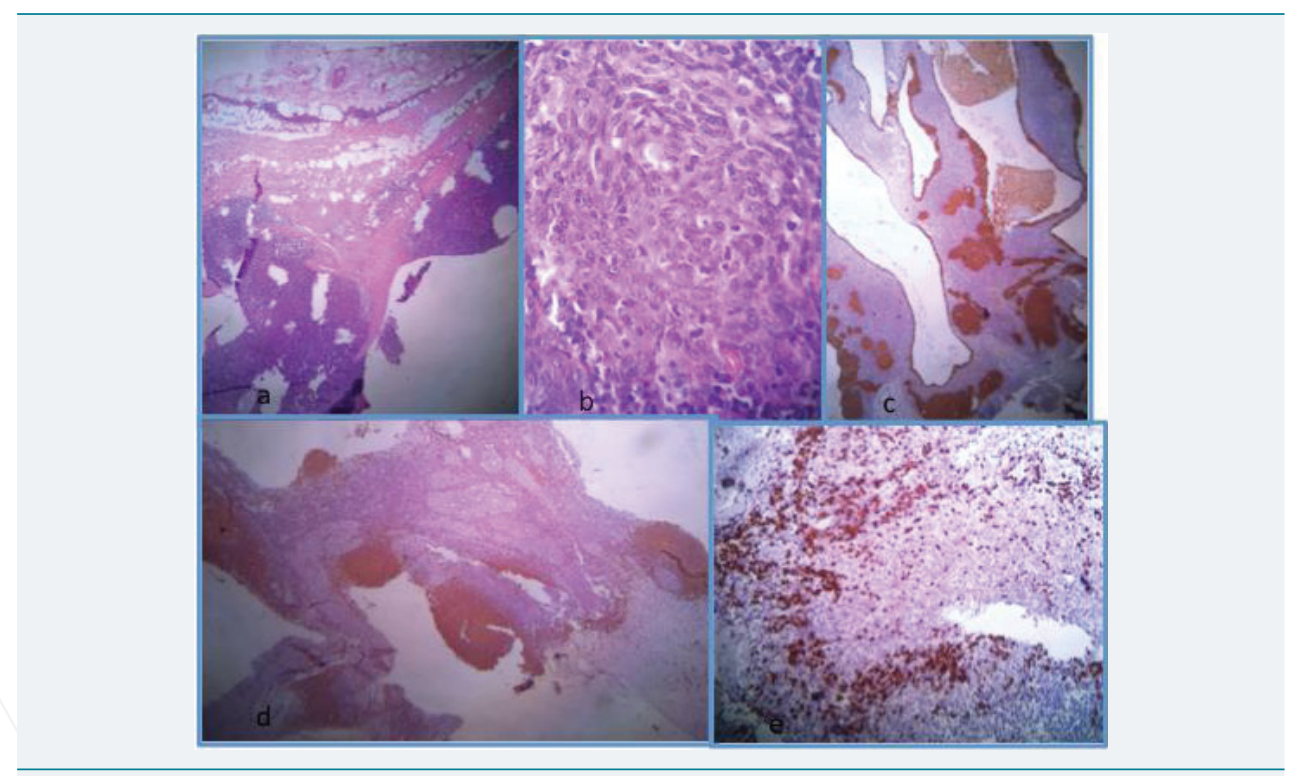

Figure 1: (a) Well limited tumour partially cystic made of epithelial nests and an abundant lymphoid stroma (HE x 250), (b) The epithelial cells are of spindle shape (HE x 400), (c) Immunohistochemical study using the cytokeratin antibody and highlighting the epithelial nests (HE x 250), (d) Immunohistochemical study using the CD20 antibody and highlighting the lymphoid follicles (HE x 250), (e) Immunohistochemical study using the Tdt antibody and highlighting the immature lymphocytes (HE x 250).

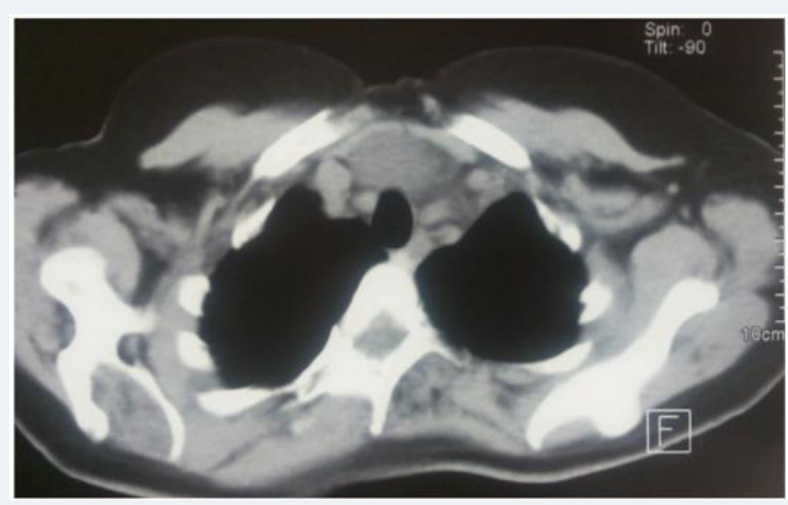

Figure 2: CT-scan showing a well limited anterior and mediastinal mass. 
of mature plasma cells. The epithelial nodules are composed of slender or plump spindle cells with bland looking oval nuclei and inconspicuous nucleoli. Rosette formation of epithelial cells may be seen. Nodules contain few interspersed lymphocytes. There are no Hassall corpuscles ou perivascular spaces. Mitotic activity is absent or minimal. Micro- and macrocystic areas, particularly in subcapsular localization, are common. Cystic thymomas should be distinguished from nonneoplastic congenital and acquired thymic cystic and other primay thymic neoplasms undergoing extensive cystic degeneration. It is important not to misinterpret the apparent infiltration of surrounding mediastinal structures that results from the inflammatory changes that often accompany these tumors as evidence of aggressive or malignant behavior [5-7].

They are distinguished from the other types of thymomas by the micronodular arrangement of the epithelial cells and the abundance of the lymphoid stroma which is prominent and characterized by germinal center formation. This characteristic of the stroma is correlated to the host immune response by some authors [8]. Others report the role of Langherans Cells that seem to migrate to the stroma in such a tumour, where they mature and form clusters with $\mathrm{T}$ lymphocytes to activate them resulting in lyphoid follicle formation [9]. The diagnosis is based on the microscopic exam of the surgical specimen. A rare observation diagnosed on a trans-thoracic biopsy has been reported in the literature [10]. Microscopic diagnostic criteria include the epithelial lobules with various shape of cells and the abundance of the stroma. Tateyama and coworkers divided these tumours according to the epithelial cells' shape into 4 groups: spindle epithelial cells, spindle and polygonal epithelial cells, polygonal epithelial cells and lympho-epithelial like carcinoma [8]. Our case belongs to the group 1 according to this subdivision. The cystic degenaration of these tumours, like in our case, hasn't been described. Other particular features such as the association of a micronodular thymoma and a thymic cyst or to a type A thymoma has been reported [11,12]. The implication of the Epstein barr virus has been described because of their relative high incidence in oriental countries in comparison with European ones [3]. The mainstay treatment is based on surgical resection as it is the case in thymomas. The long-term outcome after surgical resection currently remains unclear. Some authors report that epithelial cells of micronodular thymoma can express abnormal chemokine resulting in the recruitement of MALT, the emergence of monoclonal B cells and eventually the development of mediastinal lymphomas [12].

\section{REFERENCES}

1. Marx A, Chan JK, Coindre JM, Detterbeck F, Girard N, et al. The 2015 World Health Organization Classification of Tumors of the Thymus: Continuity and Changes. J Thorac Oncol. 2015; 10: 13831395. Ref.: https://goo.gl/XA01c1

2. Nakamura $\mathrm{S}$, Tateyama $\mathrm{H}$, Taniguchi $\mathrm{T}$, Ishikawa $\mathrm{Y}$, Kawaguchi $\mathrm{K}$, et al. Multilocular Thymic Cyst Associated With Thymoma. A Clinicopathologic Study of 20 Cases With an Emphasis on the Pathogenesis of Cyst Formation. Am J Surg Pathol. 2012; 36: 1857-1864. Ref.: https://goo.gl/WOMJrd

3. Marx A, Ströbel Ph, Marino M, Eimoto T, Harris NL, et al. Tumours of the thymus-Thymomas. Chapter 3. Micronodular thymoma with lymphoid stroma. 167-168.

4. Suster S, Moran CA. Micronodular thymoma with lymphoid B-cell hyperplasia. clinicopathologic and immunohistochemical study of eighteen cases of a distinctive morphologic variant of thymic epithelial neoplasm. Am J Surg Pathol. 1999; 23: 955-962. Ref.: https://goo.gl/87Zfas

5. Suster S, Rosai J. Cystic thymomas. A clinicopathlogic study of ten cases. Cancer. 1992; 69: 92-97. Ref.: https://goo.gl/fpt38W

6. Planelles A, Aranda Fl, Córdoba C, Aboumar A, Payá A. Micronodular thymoma with lymphoid B-cell hyperplasia. Report of a case. Rev Esp Patol. 2007; 40: 113-116.

7. Strobel $P$, Marino $M$, Feuchtenberger $M$, Rouzière $A S$, Tony $H P$, et al. Micronodular thymoma an epithelial tumour with abnormal chemokine expression setting the stage for lumphoma development. J Pathol. 2005; 207: 72-82. Ref.: https://goo.gl/o2YLMH 
8. Tateyama H, Saito $\mathrm{Y}$, Fujii $\mathrm{Y}$, Okumura $\mathrm{M}$, Nakamura $\mathrm{K}$, et al. The spectrum of micronodular thymic epithelial tumours with lymphoid B-cell hyperplasia. Histopathology. 2001; 38: 519-527. Ref.: https://goo.gl/Xbyl9V

9. Zhu $P$, Yan $F, A o$ Q. Langerhans cells proliferation in ectopic micronodular thymoma with lymphoid stroma: a case report. Int J Clin Exp Pathol. 2014; 7: 7262-7267. Ref.: https://goo.gl/21Elhb

10. Chen CW, Chuang SS, Pan ST. Micronodular Thymoma with Lymphoid Stroma Diagnosed with Core Needle Biopsy. A Case Report. Anal Quant Cytopathol Histpathol. 2015; 37: 206-210. Ref.: https://goo.gl/YtLZUm

11. Cha YJ, Han J, Kim J, Lee KS, Shim YM. A rare case of mixed type a thymoma and micronodular thymoma with lymphoid stroma. J Pathol Transl Med. 2015; 49: 75-77. Ref.: https://goo.gl/4jCr2z

12. Kim NR, Lee JI, Ha SY. Micronodular thymoma with lymphoid stroma in a multilocular thymic cyst: a case study. Korean J Pathol. 2013; 47: 392-394. Ref.: https://goo.gl/4pp4I4 